\title{
A Interface entre Saúde e Educação: percepções de educadores sobre educação inclusiva
}

\author{
Carla Cilene Baptista da Silva \\ Universidade Federal de São Paulo, Campus Baixada Santista -Santos - SP - Brasil \\ Elaine Soares da Silva Molero \\ Prefeitura Municipal de Cabreúva - Secretaria de Educação - Cabreúva - SP - Brasil \\ Marcelo Domingues Roman \\ Universidade Federal de São Paulo, Campus Baixada Santista - Santos - SP - Brasil
}

\begin{abstract}
Resumo
A Política Nacional de Educação Especial na Perspectiva da Educação Inclusiva preconiza a articulação entre serviços de saúde e educação para atendimento a necessidades educacionais especiais. A partir dessa perspectiva, o objetivo deste artigo é refletir sobre problemas relatados por educadores que concretizam esta política, sobretudo no que concerne às inter-relações entre saúde e educação. Para isso, são apresentados resultados de uma pesquisa em que foram entrevistadas oito professoras da rede pública municipal de Santos (SP) que ensinavam alunos com deficiência e/ou transtorno global do desenvolvimento. As entrevistas abordam uma insuficiência de articulação entre as duas áreas, permanecendo a saúde na posição de saber especializado supostamente capaz de sanar as mazelas da educação, o que fortalece processos de patologização e soluções medicalizantes, evitando, assim, o questionamento e rearranjo de práticas educacionais. O artigo aponta para a necessidade de uma efetiva colaboração entre saúde e educação, em que ambas conservem suas especificidades e se enriqueçam reciprocamente.
\end{abstract}

Palavras-chave: Educação inclusiva; saúde; interdisciplinaridade.

\section{The interface between health and education: teacher perceptions about inclusive education}

\begin{abstract}
The National Policy on Special Education in Inclusive Education Perspective advocates the linkage between health and education services to attend the special educational needs. From this perspective, the purpose of this article is to reflect about the problems reported by educators who embody this policy, especially with regard to the interrelationships between health and education. For this, the results are presented from a survey in which they interviewed eight teachers from municipal public schools in Santos (SP) who taught students with disabilities and / or pervasive developmental disorder. The interviews cover a lack of coordination between the two areas, maintaining the health in the position of expertise supposedly able to cure the ills of education, which strengthens pathological processes and medicalized solutions, thus avoiding the questioning and rearrangement educational practices. The article points to the need for effective collaboration between health and education, where both retain their specificities and enrich each other.
\end{abstract}

Keywords: Inclusive education; health; interdisciplinarity.

\section{La Interface entre Salud y Educación: percepciones de educadores sobre educación inclusiva}

\begin{abstract}
Resumen
La Política Nacional de Educación Especial en la Perspectiva de la Educación Inclusiva preconiza la articulación entre servicios de salud y educación para atención a necesidades educacionales especiales. A partir de esa perspectiva, el objetivo de este artículo es reflexionar sobre problemas relatados por educadores que concretizan esta política, sobre todo en lo que dice respecto a las inter-relaciones entre salud y educación. Para eso, son presentados resultados de una investigación en que se entrevistaron a ocho profesoras de la red pública municipal de Santos que enseñaban alumnos con deficiencia y/o trastorno global del desarrollo. Las entrevistas abordan una insuficiencia de articulación entre las dos áreas, permaneciendo la salud en la posición de saber especializado supuestamente capaz de sanar las desgracias de la educación, lo que fortalece procesos de patologización y soluciones por medicamentos, evitando, así, el cuestionamiento y reacomodamiento de prácticas educacionales. El artículo apunta hacia a la necesidad de una efectiva colaboración entre salud y educación, en que ambas conservan sus especificidades y se enriquezcan recíprocamente.
\end{abstract}

Palabras clave: Educación inclusiva; salud; interdisciplinaridad. 


\section{Introdução}

Este artigo é um recorte do trabalho de conclusão de curso (TCC), que em linhas gerais procurou investigar como professores da rede municipal de ensino fundamental de Santos entendiam a educação inclusiva, buscando conhecer as dificuldades existentes e as necessidades apontadas pelos profissionais, além de buscar compreender como os professores participantes vislumbravam as possibilidades de interface entre as áreas da saúde e da educação na perspectiva da inclusão.

Aqui serão apresentados apenas os dados relativos à interface entre as áreas em questão. Com esse enfoque, pretendeu-se explorar as opiniões dos professores acerca das práticas existentes entre as áreas da saúde e da educação no município de Santos, com relação ao processo de escolarização de crianças com deficiência e transtorno global do desenvolvimento, assim como as expectativas dos participantes em relação às possíveis contribuições das profissões da área da saúde formadas pelo campus Baixada Santista, da Universidade Federal de São Paulo (UNIFESP), aos processos de inclusão escolar.

\section{A Interface entre Saúde e Educação em tempos de Inclusão}

A relação entre as áreas da saúde e da educação tem por vezes se resumido a uma demanda de perguntas e respostas, em que dificuldades diárias do cotidiano escolar são convertidas em diagnóstico individual ou quadro patológico que com o apoio da saúde poderia ser resolvido.

Conforme nos mostra Machado (2006), o trabalho da Psicologia, serviço tão demandado pela escola, tem centrado suas atenções no sujeito e em seu funcionamento psíquico, de forma a justificar aquilo que acontece nas relações institucionais como algo causado apenas pelas características individuais dos sujeitos. Esta prática tem por consequência a isenção do sistema social, econômico e político da responsabilidade pela produção de desigualdades de todos os tipos, culpabilizando o indivíduo isoladamente por aquilo que o acomete.

De acordo com Sant'Ana (2005), professores consideram o apoio de especialistas como um aspecto fundamental na atuação com crianças que apresentam deficiências, considerando-se despreparados para a inclusão, tendo em vista que não teriam aprendido as práticas educacionais essenciais à promoção da inclusão.

Se pensarmos nesta hipótese, de que a educação não está preparada para lidar com questões essenciais da inclusão, e fazendo o caminho reverso, ou seja, partindo da saúde para considerar aspectos educacionais, podemos observar o que apontam Marçal e Silva (2006) quando relatam experiências de um atendimento na rede pública de saúde mental. Observou-se uma completa incompreensão da queixa escolar, com uma visão essencialmente clínica e desconectada da escola, prevalecendo uma concepção de que existem principalmente questões emocionais por trás da queixa e que a família está diretamente relacionada às dificuldades de aprendizagem dos filhos.

Conforme mostra Sant'Ana (2005), é evidente a necessidade de que os professores sejam instrumentalizados a fim de atender às peculiaridades apresentadas pelos alunos, de acordo com suas individualidades. Entretanto, as maiores dificuldades no trabalho docente em atendimento educacional especializado não parecem dizer respeito à questão do diagnóstico, mas, como nos afirma Machado (2006), se relacionam a questões como: discriminação e receio diante de alunos que apresentam dificuldades ou deficiências, preconceito que esses alunos sofrem no cotidiano escolar, dificuldade em se manter um trabalho conjunto com as professoras de classe regular ou, ainda, o fato de algumas professoras delegarem ao atendimento educacional especializado todo o trabalho educativo.

Ferreira (2007) apresenta alguns apontamentos para se fugir deste embate, tais como a necessidade de uma pedagogia centrada na criança, baseada em suas habilidades, e não em suas deficiências, incorporando conceitos como interdisciplinaridade, conscientização/sensibilização e colocando de lado práticas cristalizadas e institucionalizadas, que só servem para lidar com a homogeneidade, de forma que é necessário colocar em dúvida valores, verdades e, principalmente, hábitos tradicionais.

Sabemos que para garantir uma educação efetivamente inclusiva, em um ambiente escolar não-restritivo, é necessário o envolvimento de todos os membros da equipe escolar, assim como efetiva participação da comunidade no planejamento de ações e programas voltados à temática. Entretanto, convém destacar que professores apresentam funções essenciais na estrutura e no funcionamento do sistema educacional e suas opiniões podem fornecer subsídios relevantes para a compreensão de como tem ocorrido o processo de inclusão, em um âmbito que está além das legislações, o cotidiano escolar. Podemos dizer que ganham especial relevância os discursos e ações dos professores, porque, como nos mostra Jesus (2004), em última instância, são eles que, no meio de seus medos, dúvidas, ansiedades, disponibilidades, acolhimentos e possibilidades, assumem os alunos em suas salas de aula.

Em face dessas considerações, vale esclarecer que este trabalho é parte de um projeto de extensão interdisciplinar intitulado "Educação Inclusiva: integrando atenção interdisciplinar em saúde no atendimento educacional especializado", que envolveu estudantes e docentes dos cursos de Nutrição, Psicologia, Terapia Ocupacional e Fisioterapia, em parceria com a Secretaria de Educação do Município de Santos (SEDUC), visando inicialmente identificar as demandas dos educadores da rede municipal do ensino fundamental, associado a um levantamento de experiências existentes relativas à Educação Inclusiva, para posterior apresentação dos resultados e de propostas de discussão e reflexão sobre questões correlatas ao tema. Tal processo ofereceu subsídios à equipe executora para a elaboração das etapas subsequentes do projeto. 
A partir desse contexto, o objetivo deste artigo é refletir sobre problemas relatados por professores de ensino fundamental, no que concerne às inter-relações entre saúde e educação, especialmente em relação às contribuições da Educação Física, Fisioterapia, Nutrição, Psicologia e Terapia Ocupacional ao processo de inclusão escolar de crianças com deficiência e transtorno global do desenvolvimento.

\section{Método}

Participaram deste estudo oito professoras de salas regulares de ensino fundamental, atuantes em três escolas da rede municipal da cidade de Santos, sendo que estas tinham, no momento da pesquisa, crianças com deficiência e/ou transtorno global do desenvolvimento em suas classes. Ainda quanto ao perfil das participantes, o menor e o maior tempo em anos de trabalho no exercício da prática pedagógica destas são de 07 e 30 anos, respectivamente, seja na rede estadual ou municipal.

Ao longo do primeiro semestre de 2010 , foram realizadas entrevistas semiestruturadas com as participantes, nas próprias escolas e em horários escolhidos por elas. Para a realização das entrevistas, foi utilizado um roteiro de questões orientadoras, além de equipamento de gravação, para registro dos dados e posterior transcrição e análise do material.

O roteiro pretendeu focalizar diversas dimensões relativas à Educação Inclusiva, dentre elas as inter-relações existentes entre as áreas da saúde e da educação, assim como expectativas de professores em relação às contribuições da Educação Física, Fisioterapia, Nutrição, Psicologia e Terapia Ocupacional ao processo de inclusão escolar de crianças com deficiência ou transtorno global do desenvolvimento.

Após a transcrição dos relatos, foi feita uma leitura ampla do material obtido. Em seguida, realizou-se a análise de conteúdo, segundo a proposta de Bardin (2002).

\section{Resultados e Discussão}

No bojo das discussões acerca de inclusão escolar de crianças com deficiência e transtorno global de desenvolvimento e sua aproximação efetiva com a área da saúde, é unânime no discurso das entrevistadas a visão de distância entre os dois campos, sendo que nenhuma delas relatou identificar qualquer tipo de aproximação, como podemos observar no relato da professora 2: "...eu vejo assim que é como se fossem duas coisas assim que tivessem polos opostos, sabe. "

As únicas descrições de contatos com profissionais da saúde referem-se a eventos esporádicos, campanhas odontológicas principalmente, nas quais são feitas avaliações da saúde bucal das crianças, orientações e palestras para alunos, famílias e professores. Neste sentido, uma das professoras vislumbra a possibilidade de estender esta atuação para outras áreas do conhecimento no campo da saúde.

Esta consideração vem no sentido do que é proposto pelo Plano Nacional de Educação, estabelecido pela Lei nº 8035
(2010), que preconiza especificamente na Meta 4 a universalização do acesso a educação básica ao público-alvo da educação especial, na perspectiva da educação inclusiva, reforçando,para tanto, o que é apontado nos itens 4.5, 4.10, 4.11 e 4.12, que tratam de estratégias que visam a garantia da articulação intersetorial entre as políticas públicas e o desenvolvimento de novas metodologias, materiais e equipamentos, assim como preconizam o envolvimento de instituições acadêmicas e profissionais das redes de educação, saúde e assistência social para o desenvolvimento de centros integrados de pesquisa.

Assim, as ações conjuntas de profissionais das áreas da saúde, assistência social e educação, são fundamentais para apoiar o trabalho das unidades de ensino, caminhando para além de campanhas meramente informativas ou diagnósticas, de modo a potencializar a ação de cada profissional em suas especificidades, com uma atuação colaborativa e que supere a fragmentação dos saberes e fazeres nas diferentes instâncias do atendimento.

Quatro entrevistadas relatam não ter contato algum com profissionais de instituições especializadas que atendem muitos dos alunos com deficiência e transtorno global do desenvolvimento matriculados na rede regular de ensino. Esses profissionais pertencem a órgãos da rede municipal de saúde e são responsáveis por avaliação diagnóstica e acompanhamento de alunos encaminhados pela escola. As entrevistadas que afirmam trocar algum tipo de informação com esses profissionais, relatam fazê-lo por meio da orientadora educacional, do envio de relatórios ou de um caderninho de recados que acompanha o aluno entre as duas instituições, ou ainda por meio da família. Cabe destacar que apenas uma das entrevistadas acredita que estas vias sejam suficientes para uma prática integrada.

$\mathrm{Na}$ visão das professoras, este contato se faz necessário no sentido do acompanhamento integral e de atenção às necessidades dos alunos, em uma via de mão dupla, de modo que ao professor seria possível inteirar-se da condição clínica dos estudantes atendidos, os progressos, as dificuldades, o desenvolvimento socioemocional, psicomotor, de acordo com o tipo de atendimento. De modo geral, manifestaram interesse em compreender o aluno do ponto de vista clínico, visando adequação de métodos, materiais e conteúdos no campo pedagógico.

Além disso, os professores veem nesses profissionais uma possibilidade de se certificarem do que está sendo feito junto ao aluno em sala de aula, depositando neles a expectativa de amparo e aval em relação a sua prática. Essa postura se relaciona com a falta de preparo relatada, a falta de suporte para o professor formular adaptações no atendimento ao aluno com deficiências e transtornos globais do desenvolvimento, principalmente metodológicas, curriculares e nos processos de avaliação pedagógica, fortalecendo a crença de que o profissional da área da saúde teria as respostas para efetivação e sucesso do processo de inclusão. Conforme ilustra o relato da professora 1: “... E dependendo do problema do aluno, se você não conhece muito sobre aquilo, fica difícil você tentar ajudar, de repente você acha que tá fazendo a coisa certa e não ta, né?". 
Os resultados encontrados corroboram o que é apresentado por Sant'Ana (2005) quando evidencia uma preocupação dos professores em relação à falta de orientação no atendimento aos alunos inclusos, de forma que, mesmo quando existe algum tipo de contato com profissionais especializados da área da saúde, acreditam ser insuficiente para atendimento das demandas surgidas durante o processo na perspectiva inclusiva, não se configurando, portanto, em um apoio efetivo ao processo. Evidenciam-se, assim, dificuldades decorrentes da insuficiência de articulação entre profissionais de diferentes áreas, de modo que a falta de atividades conjuntas ainda se configura como importante obstáculo para a efetivação de ações e projetos comprometidos com os princípios da educação inclusiva.

Ainda no sentido da importância de um trabalho integrado entre saúde e educação e da necessidade de completude da atuação junto ao aluno, algumas entrevistadas sentem por vezes que sua atuação pedagógica está defasada, aquém das necessidades ou capacidades do aluno, assim como observam que o atendimento da saúde não vem ao encontro da prática pedagógica, de modo que o desenvolvimento da criança estaria sendo fragmentado por estas duas instâncias de cuidado. Conforme exposição da professora 4: "...sem ter essa parceria, eu fico com uma ideia de aluno aqui e ele com uma ideia de paciente lá, e fica muito só no papel. "; ou como relatado pela professora 1:

... às vezes você encaminha o aluno, faz o seu relatório, e eles dão um parecer assim, que não concorda exatamente com o que você está falando, mas também não explicam os motivos, fica uma discrepância de você fazendo uma coisa e eles colocarem outra. Então fica tudo assim muito distante, tudo muito separado. E a criança fica perdida no meio de tudo isso.

Este relato nos remete ao que Machado (2006) coloca em discussão quando questiona o fato de relatórios psicológicos apresentarem conteúdo que não coincide com o que é observado no cotidiano escolar da criança; além disso, busca compreender o porquê de tantos laudos serem demasiadamente parecidos.

Não obstante a discrepância sentida pelas professoras, entre o que dizem os laudos e o que observam diariamente em relação a seus alunos, os relatos referem-se a uma busca de respostas advindas da saúde para processos que se engendram na sociedade e se refletem e se reproduzem na escola. Assim, duas entrevistadas queixam-se da falta de laudo para um grande número de alunos que, segundo elas, caso fossem submetidos a processo de avaliação diagnóstica, certamente apresentariam algum "problema". Relatam ainda que a inexistência do diagnóstico dificulta o trabalho em sala de aula, pois não conseguem identificar exatamente quais são as dificuldades do aluno e, em consequência disto, não sabem como encaminhar o trabalho junto ao educando.

Neste sentido, alguns questionamentos valiosos à prática de profissionais da saúde são trazidos por Machado (2006), refletindo de maneira crítica quanto à real importância do laudo como auxílio no fazer pedagógico. A autora questiona se o professor efetivamente precisa desta avaliação para trabalhar com a criança, de forma que é necessário, na perspectiva da inclusão, centrar menos atenção nas limitações e problemáticas do ponto de vista individual, culpabilizante e patologizante para, antes, compreender as práticas cristalizadas e baseadas em parâmetros ideais de aluno, o que permite centrar esforços no desenvolvimento de suas potencialidades. Além disso, é necessário atentar para as perigosas consequências que um laudo emitido por um profissional da saúde pode acarretar. Como nos ensina Patto (1997), laudare significa aprovar, ou seja, tudo funciona como se houvesse uma concordância do profissional de saúde, frequentemente o psicólogo, em relação ao que o professor já apresentava como crença, de modo que o discurso padronizado do primeiro, no laudo, tem a pretensão de revestir de cientificidade um rótulo atribuído ao aluno encaminhado, amiúde selando seu destino e, no limite, empurrando-o para fora dos bancos escolares.

Marçal e Silva (2006), analisando o quadro a partir da perspectiva da saúde, relatam que as queixas escolares que justificam encaminhamentos para avaliação e tratamento falam essencialmente de indisciplina dos alunos em sala de aula, de hiperatividade e de dificuldades na aprendizagem, entretanto, conforme apontado pelos autores, “... o que é preciso analisar não são os 'problemas de aprendizagem', mas o 'processo de escolarização'." (p.128). Neste sentido, observamos que se atribuem a responsabilidade às crianças que "não aprendem, são desobedientes, possuem algum déficit", ficando ausentes da discussão os processos de escolarização. Desta forma, segundo os autores, a escola ficaria à espera de que os psicólogos ou médicos neurologistas, psiquiatras e afins, resolvessem a situação assepticamente.

Tendo em vista o que vimos discutindo em relação à importância de um trabalho integrado que percorra as diversas dimensões do atendimento, procuramos, ainda que minimamente, compreender as concepções dos professores com relação a determinadas profissões da área da saúde, uma vez que este trabalho é fruto de um projeto de Extensão que visa integrar atenção interdisciplinar em saúde ao atendimento educacional especializado, e que envolveu os cursos de Educação Física, Fisioterapia, Nutrição, Psicologia e Terapia Ocupacional.

Em relação à Educação Física, as entrevistadas atribuem a esta área de atuação o desenvolvimento, junto aos alunos, de habilidades esportivas, de socialização e inserção em jogos cooperativos. Além disso, veem a prática esportiva como promotora de saúde para todos, sendo que do ponto de vista da inclusão acreditam que seja essencial uma mudança nas diretrizes curriculares na formação acadêmica desses profissionais, pois mostram-se, segundo elas e com algumas exceções, despreparados para atuação junto aos alunos com deficiência e transtorno global do desenvolvimento, pois são incapazes de adaptar as atividades de modo a contribuir e viabilizar a inclusão dessas crianças também no espaço das quadras desportivas. 
A Fisioterapia por sua vez, segundo três entrevistadas, apesar de ser considerada importante para alunos com deficiência física, não está prevista internamente nas escolas, apenas no espaço das instituições especializadas para atendimento clínico. Em contrapartida, as demais entrevistadas vislumbram a inserção do fisioterapeuta nas instituições educacionais no sentido de diagnosticar, encaminhar e avaliar periodicamente os alunos, assim como auxiliar nos processos de correção postural e ainda viabilizar adaptações físicas e materiais na escola para melhor acomodação dos alunos com dificuldades motoras.

No que se refere à Nutrição, os relatos das professoras a colocam, na maior parte, restrita ao espaço da cozinha cumprindo a função de instruir as merendeiras. Entretanto, a Nutrição extrapola, em alguns relatos, este espaço, avistando-se sua atuação junto a professores, familiares e alunos, no sentido de orientação para hábitos alimentares saudáveis, pois tem crescido cada vez mais o número de alunos com obesidade. Apenas uma professora considera uma possibilidade mais ampla de atuação junto a alunos, secretaria de educação e às equipes que trabalham nas cozinhas das escolas, no sentido de proporcionar aos alunos maior autonomia na hora da alimentação escolar, com "bandejões", por exemplo, tendo em vista que muitos alunos não se alimentam por não terem oportunidade de escolher no cardápio do dia o que querem comer, consumindo salgadinhos industrializados, refrigerantes e afins, ou simplesmente se isentando do horário da refeição na escola.

A Terapia Ocupacional é considerada essencial para o processo de inclusão escolar, sendo citadas atribuições tais como adaptações de rotinas para alunos com deficiência e transtorno global do desenvolvimento, assim como auxílio aos professores na compreensão do aluno do ponto de vista físico e psíquico. Apenas uma professora relatou não conhecer o trabalho da Terapia Ocupacional, apesar de já ter ouvido falar e de ter alunos que são atendidos por esse profissional em instituições especializadas, evidenciando, mais uma vez, a cisão existente entre o atendimento nas referidas instituições e o trabalho pedagógico desenvolvido na escola.

No Brasil, a atuação da Terapia Ocupacional na educação regular é tão recente quanto o princípio da educação inclusiva. Portanto, é compreensível o desconhecimento das possibilidades de atuação da profissão entre as entrevistadas neste estudo. Por outro lado, se faz necessário refletir sobre os possíveis papéis e atribuições deste profissional nesse contexto. Rocha (2007) aponta que o enfoque deve ser dado ao sujeito coletivo e não unicamente ao aluno com deficiência. Assim, a intervenção terapêutica ocupacional no contexto educacional visa o fortalecimento da potência de ação dos indivíduos envolvidos, facilitando a elaboração de soluções para os impasses a partir do próprio grupo, utilizando diferentes recursos e equipamentos da comunidade.

Entretanto, cabe atentarmos para o fato de que a prática do terapeuta ocupacional no contexto educacional pode se tornar excludente e segregadora, ao invés de potencializadora de ações transformadoras. Portanto, o terapeuta ocupacional deve refletir constantemente sobre sua atuação, apresentando uma visão crítica que considere os vários fatores relacionados aos contextos educacionais e sociais, como o ambiente escolar, a equipe educacional, a relação entre a escola e os familiares, o projeto pedagógico, e principalmente, as práticas existentes e as possibilidades relativas à interface entre saúde e educação.

No relato das entrevistadas, observamos diversas expectativas em relação à atuação do psicólogo junto à escola, provavelmente por essa ser uma profissão que tradicionalmente tem, como uma de suas áreas de atuação, a educação. Embora essa atuação seja frequentemente realizada a partir de equipamentos de saúde e, consequentemente, norteada por modelos clínicos individuais, as entrevistadas demandam maior dedicação às demandas escolares, não estabelecendo clara distinção sobre a inserção institucional do psicólogo, ou seja, não definindo se ele deveria pertencer à área da saúde ou se deveria ser vinculado diretamente à educação. Nesse sentido, é citada a necessidade de auxílio para identificação de casos e realização de diagnósticos dentro da própria instituição escolar, tendo em vista a burocracia e a demora no retorno dos resultados para a escola por parte dos centros diagnósticos disponibilizados para encaminhamentos do atendimento público na rede municipal.

Encontramos ainda a expectativa de que se disponibilizasse, nas escolas, atendimento para professores como suporte no trabalho junto aos alunos com deficiência e transtorno global do desenvolvimento, sendo que as professoras relatam insegurança, sobrecarga, sofrimento e vulnerabilidade diante dos processos pedagógicos, principalmente na perspectiva da inclusão, sendo que, de acordo com Bartalotti e Yonezaki (2008, p.125), "O medo é fruto, muitas vezes do desconhecimento. Outras vezes, da própria experiência (que pode ser a do fracasso, a da sensação de incapacidade para lidar com algo)".

Ainda no sentido de suporte ao processo de inclusão escolar, as entrevistadas relatam uma necessidade de trabalho com os alunos e familiares, com ou sem diagnósticos, síndromes ou deficiências, de modo a disseminar no contexto escolar concepções que sigam as diretrizes da inclusão em direção à construção de cidadania, de combate à discriminação e ao preconceito.

Por fim, aparece a dificuldade de relação entre escola e família, sendo que, na concepção das entrevistadas, a desestrutura familiar, o desinteresse pela educação dos filhos, ou ainda quaisquer desajustes emocionais que venham a interferir no processo de ensino-aprendizagem seriam questões a serem contornadas por um espaço de escuta proporcionado pelo psicólogo. Além disso, seria incumbência da Psicologia o trabalho com os familiares de alunos diagnosticados ou encaminhados para avaliação, no sentido de convencê-los da necessidade de acompanhamento ou medicalização, ou seja, uma demanda para que o psicólogo confirme e compartilhe do processo de culpabilização individual ou familiar dos percalços encontrados no âmbito da instituição escolar.

Percebem-se, assim, nas expectativas acerca do trabalho do psicólogo, fortes tendências individualizantes e de desconsideração do próprio funcionamento escolar como 
produtor de dificuldades ao processo de escolarização e, portanto, também como lócus em que essas dificuldades podem ser superadas. Entretanto, a literatura científica brasileira na área da Psicologia Escolar e Educacional vem apontando, desde a década de 1980, a necessidade de superação de modelos medicalizantes para a compreensão dos problemas escolares e para a construção de novas formas de atuação do psicólogo. Essas formas de atuação podem ser realizadas por psicólogos inseridos tanto em equipamentos de saúde quanto em órgãos da própria educação, desde que tenham, como foco, as relações institucionais presumivelmente produtoras de ensino e aprendizagem. Assim, tendo por finalidade a educação de todos e para todos, a atuação do psicólogo deve se pautar pela co-responsabilização de diversos sujeitos envolvidos no ato de educar - professores, alunos, familiares, gestores, profissionais de saúde, assistência social etc. - a partir de uma série de estratégias de reflexão e ação conjuntas (Souza, Silva, \& Yamamoto, 2014).

\section{Considerações Finais}

Apesar dos avanços nos processos de educação inclusiva, observa-se ainda uma inclusão que busca se adequar aos moldes legislativos, definidos pelos professores como "lindo e perfeito no papel", mas que, na prática, tem se apresentando de modo fragmentado em diferentes instâncias da atenção à criança com deficiência e/ou transtorno global do desenvolvimento. Diversas áreas do conhecimento se envolvem no atendimento a esses alunos, não obstante estas instâncias pouco ou nada se conversam, ocorrendo apenas o encaminhamento de crianças da educação para a saúde, onde são diagnosticadas, rotuladas e devolvidas para a escola, sem a elaboração e efetivação de planos conjuntos de atendimento que caminhem em direção ao processo de uma educação inclusiva que garanta ações intersetoriais.

Desta forma, parece que tudo estará documentado e justificado, desde que a saúde legitime as dificuldades encontradas na educação por meio do diagnóstico do aluno que não se adéqua aos moldes da escola, não havendo, assim, questionamento sobre as práticas institucionais que não dão conta de atender aos alunos em suas individualidades. Compreende-se que este processo de busca por respostas imediatas e assépticas no campo da saúde, apenas no sentido de legitimar diagnósticos, distancia e dificulta cada vez mais o processo de inclusão escolar, visto que isenta os indivíduos da ação educativa, pois alunos são tidos como constitucionalmente problemáticos e professores tornam-se reféns da condição clínica de seus alunos e da falta de preparo para lidar com esta situação de atendimento diferenciado. Neste sentido, o processo caminha para lugar algum, comprometendo a efetividade da inclusão e tornando-a apenas aparente.

A busca por integração entre saúde e educação para promoção de um sistema educacional efetivamente inclusivo exige uma série de estratégias coordenadas, a partir das quais os sujeitos terão condições de desenvolver um trabalho coletivo em prol da educação de todos. Entre essas estratégias, certamente estão a necessidade de reformulação da formação de profissionais de saúde - que precisam compreender os problemas e demandas escolares -, a articulação entre instituições acadêmicas e redes de serviços para o desenvolvimento de pesquisas, métodos e formação contínua, e a reestruturação do funcionamento escolar, a fim de que valorize professores e alunos e assim ofereça melhores condições de um fazer educativo que promova o desenvolvimento de todos.

\section{Referências}

Bardin, L. (2002). Análise de conteúdo. Lisboa: Edições 70.

Bartalotti, C.C. \& Yonezaki, C. (2008). Concepções de profissionais de educação e saúde sobre educação inclusiva: reflexões para uma prática transformadora. O Mundo da Saúde, 32(2), 24-130.

Ferreira, M.E.C. (2007). O enigma da inclusão: das intenções às práticas pedagógicas. Educação e Pesquisa, 33(3), 543-560.

Jesus, D.M. (2004). Atuando em contexto: o processo de avaliação numa perspectiva inclusiva. Psicologia e Sociedade, 16(1), 37-49.

Machado, A.M. (2006). Educação Inclusiva: de quem e de quais práticas estamos falando? Em C.R. Baptista (Org.), Inclusão e Escolarização: múltiplas perspectivas. Porto Alegre: Mediação.

Marçal, V.P.B. \& Silva, S.M.C. (2006). A queixa escolar nos ambulatórios públicos de saúde mental: práticas e concepções. Psicologia Escolar e Educacional, 10(1), 121-131.

Patto, M.H.S. (1997). Para uma crítica da razão psicométrica. Psicologia USP, 8(1), 47-62.

Projeto de Lei n. 8035 de 20 de dezembro de 2010 (2010). Aprova o Plano Nacional de Educação para o decênio 2011-2020 e dá outras providências. Brasília, DF: Câmara dos deputados.

Rocha, E.F. (2007). A terapia ocupacional e as ações na educação: aprofundando interfaces. Revista de Terapia Ocupacional da Universidade de São Paulo, 18(3), 122-127.

Sant'Ana I.M. (2005, maio/agosto). Educação inclusiva: concepções de professores e diretores. Psicologia em Estudo, 10(2), 227-234.

Souza, M.P.R., Silva, S.M.C., \& Yamamoto, K. (Orgs.) (2014). Atuação do psicólogo na educação básica: concepções, práticas e desafios. Uberlândia: EDUFU.

Recebido em: 25/11/2014

Reformulado em: 10/06/2015

Aprovado em: 07/12/2015 


\section{Sobre os autores}

Carla Cilene Baptista da Silva (carlaci@gmail.com)

Docente do curso de Terapia Ocupacional da Universidade Federal de São Paulo, Campus Baixada Santista. Doutora em Psicologia Escolar e do Desenvolvimento Humano.

Elaine Soares da Silva Molero (nani_ia@hotmail.com)

Psicóloga da Prefeitura Municipal de Cabreúva - Secretaria de Educação

Marcelo Domingues Roman (mdroman@hotmail.com)

Docente do curso de Psicologia da Universidade Federal de São Paulo, Campus Baixada Santista. Doutor em Psicologia Escolar e do Desenvolvimento Humano. 
